\title{
Los lugares de memoria y las nuevas generaciones: Algunos efectos políticos de la transmisión de memorias del pasado reciente de Chile ${ }^{1}$
}

\author{
Places of memory and the new generations: Some political effects \\ of the transmission of memories of Chile's recent past
}

MARÍA J. REYES

Universidad de Chile

MARÍA A. CRUZ

Universidad de Valparaíso

FÉLIX J. AGUIRRE

Universidad de Valparaíso

\section{Cómo citar/Citation}

Reyes, M. J., Cruz, M. A. y Aguirre, F. J. (2016). Los lugares de memoria y las nuevas generaciones: Algunos efectos políticos de la transmisión de memorias del pasado reciente de Chile. Revista Española de Ciencia Política, 41, 93-1 14.

Doi: http://dx.doi.org/10.21308/recp.41.04

\section{Resumen}

El artículo se inscribe dentro de los estudios sociales de la memoria de la dictadura chilena. Se presentan los resultados de una investigación sobre la transmisión de las memorias desde la relación entre los lugares de memoria y los jóvenes. Metodológicamente se trabajó con un diseño cualitativo que incluyó dos memoriales sobre la represión política visitados por dos grupos de jóvenes a los que posteriormente se entrevistó grupalmente. Los resultados muestran un discurso que incluye un quién que recuerda, es recordado y es destinatario del pasado y un qué se rememora. Este discurso sitúa a los jóvenes como espectadores del pasado y muestra cómo

1. Esta investigación fue financiada por Fondos Semilla 2010, Universidad Diego Portales. La preparación de este artículo ha sido apoyada por Programa U-APOYA Línea 2: Concurso de Proyectos de Investigación en Ciencias Sociales, Humanidades, Artes y Educación VID 2012, CSSOC-2012-309, Universidad de Chile; Proyecto FONDECYT n. ${ }^{\circ} 11121405$, Universidad de Chile; «Beca Término de Tesis Doctoral» del Convenio de Desempeño UVA0901 para el fortalecimiento de las Humanidades, las Artes y las Ciencias Sociales de la Universidad de Valparaíso; y por Centro de Estudios Interdisciplinarios sobre Cultura Política, Memoria y Derechos Humanos, Universidad de Valparaíso. 
los memoriales son interpretados en una lógica más bien privatizada y guetizada acerca del sufrimiento de las víctimas. Se concluye que las memorias juveniles presentan una débil condición pública, por lo que la socialización política habría acrecentado la despolitización, dificultando una relación virtuosa entre memoria y ciudadanía.

Palabras clave: memoria colectiva, memoria histórica, lugares de memoria, cultura política, jóvenes, Chile.

\begin{abstract}
The present article falls within the context of social studies on the memory of the Chilean dictatorship. The text presents the results of a study on the transmission of memories from the perspective of the relationship between places of memory and young people. Methodologically, a qualitative design was used which included two memorials of political repression visited by two groups of young people who were later interviewed in group. The results reveal a discourse that includes $a$ who that remembers, is remembered, and is an addressee of the past, and $a$ what which is remembered. This discourse positions young people as spectators of the past and it shows how memorials are interpreted according to a rather privatized and ghettoized logic of the victims' suffering. It is concluded that the memories of young people have a weak public facet and that, therefore, political socialization would have increased their depolitization, making it more difficult to establish a virtuous relationship between memory and citizenship.
\end{abstract}

Keywords: collective memory, historical memory, places of memory, political culture, young people, Chile.

\title{
INTRODUCCIÓN
}

Son contadas las ocasiones en que la actualidad noticiosa puede ayudarnos a ilustrar hasta qué punto el pasado se percibe como un espacio de negociación cultural, mediatizado y generacional, en el que la memoria frecuentemente se transforma en un objeto de disputa.

Apenas unos días antes de entregar este trabajo, una nota periodística en Chile reproducía la perplejidad de un turista extranjero cuya curiosidad le había llevado a detenerse para observar el paso del cortejo fúnebre de Patricio Aylwin, presidente del primer Gobierno democrático (1990-1994) tras 17 años de una cruel dictadura cívico-militar (1973-1990). Apenas tres cuadras hacia el oriente del corazón de la capital donde se encuentra la antigua sede del Congreso Nacional, el lugar en el que sería homenajeado el exmandatario, comenzaban a reunirse los primeros cientos de manifestantes convocados por las principales asociaciones de estudiantes de enseñanza media y universitaria, en un nuevo acto de protesta por los procedimientos y propuestas del Gobierno sobre el modelo de financiamiento de la educación superior. Horas atrás, a pesar del llamamiento de diferentes parlamentarios del oficialismo y de la oposición a suspender la actividad en el contexto de los tres días de duelo oficial decretados por el Gobierno, la portavoz de 
la Confederación de Estudiantes de Chile confirmaba la decisión de mantener la jornada de movilización nacional, y añadía: «Nosotros creemos que esta temática no puede esperar [...] esta también es la lucha de la alegría que nunca llegó y que tenemos que seguir buscando construir nosotros mismos» ${ }^{2}$. Una aseveración que revela cómo los jóvenes se instalan como "destinatarios» de un legado del pasado, pero a la vez como "protagonistas del presente» (Reyes et al., 2015).

A pesar de haber transcurrido ya más de cuatro décadas desde el golpe de Estado en Chile (1973), cobra aún mayor fuerza la preocupación sociopolítca sobre cómo transmitir a las nuevas generaciones un pasado reciente marcado por la violencia y la represión política. Aunque esta preocupación se ha visto reflejada en las políticas públicas de memoria (Vinyes, 2007), entre ellas la generación de comisiones que han procurado el esclarecimiento de lo acontecido durante la dictadura ${ }^{3}$, falta aún avanzar en la construcción de una cultura política capaz de orientar la apropiación y la reconstrucción de las memorias sociales, en particular de los mecanismos que facilitan transitar desde contextos de violencia política a otros de paz (San Pedro y Baer, 2003).

Las ciencias sociales han aportado principalmente estudios sobre «vehículos de memoria» (Jelin y Langland, 2003) a la problemática de la transmisión, incluyendo los llamados «lugares de memoria» (Nora, 2009), considerados como dispositivos privilegiados para la transmisión, en la medida que ensamblan lo tangible y lo simbólico (Rilla, 2009), permitiendo que la memoria trabaje en y desde el presente (Candau, 1998). Estos estudios se han centrado principalmente en las versiones del pasado que se producen a través de los usos y apropiaciones de dichos lugares (Piper et al., 2009; Piper et al., 2012; Piper y Hevia, 2013; Piper, 2015; entre otros), siendo común en ellos sostener que las memorias construidas se organizan en torno a la experiencia de victimización marginando de sus discursos el lugar de los y las sobrevivientes y luchadores y luchadoras sociales (Piper, 2015).

Teniendo en cuenta que en este particular campo de estudios aún es marginal centrar la atención en las voces de quienes suelen considerarse como los principales «destinatarios» del proceso de transmisión -las nuevas generaciones- (Reyes, 2012), y a su vez, asumiendo que los jóvenes, a pesar de no ser protagonistas del pasado de violencia y represión política, a través de sus acciones dan forma a las memorias y olvidos de dicho pasado utilizándolo en sus luchas presentes, tal y como evidencia la aseveración de

2. Emol.com: http://www.emol.com/noticias/Nacional/2016/04/20/799002/Confech-ratifica-marcha-de-este-jueves-Es-la-lucha-de-la-alegria-que-nunca-llego.html. El énfasis es nuestro. La portavoz de los estudiantes parafrasea el popular eslogan de la campaña de televisión previa al plebiscito de 1988, que promocionó el No a la continuidad de Augusto Pinochet como Presidente de la República: «La alegría ya viene». Véase, por ejemplo, Antonio Skármeta, Los días del arcoíris, Barcelona, Planeta, 2011; María Elena Macuk Urbina, La alegría ya viene... Las representaciones sociales acerca del plebiscito de 1988 en Chile, tesis para obtener el grado en maestría en Ciencias Sociales, FLACSO MÉXICO, 2014. Disponible en: http://200.76.166.3:8080/dspace/handle/123456789/3549

3. Comisión de Verdad y Reconciliación (1990), Mesa de Diálogo (1999), Comisión de Prisión Política y Tortura (2003). 
la dirigente estudiantil que mencionamos anteriormente, el presente artículo tiene por objetivo exponer parte de los resultados de una investigación que tuvo por objeto de estudio la dialogía que se produce entre los lugares de memoria y los jóvenes. En concreto, se analizarán los discursos que los jóvenes producen al visitar dos memoriales instalados en Santiago de Chile: el memorial del Detenido Desaparecido y del Ejecutado Político (DDEP) y el monumento Mujeres en la Memoria (MM)

El propósito del artículo es contribuir al conocimiento sobre cómo las generaciones que no vivieron directamente la dictadura despliegan ciertas subjetividades sobre el pasado reciente a propósito de determinados lugares de memoria, con el fin de poner en discusión ciertos efectos políticos asociados a las políticas de memoria en el Chile de la postdictadura.

De este modo, el artículo parte presentando los principales referentes teóricos que guiaron la investigación, para seguir con los antecedentes metodológicos que permitieron tanto la producción como el análisis de los discursos generados por los jóvenes al visitar los memoriales. Luego, al revisar el rol de los jóvenes a partir de una selección de los resultados concentrados de su discurso sobre qué se rememora, quién recuerda, quién es recordado y quién es el destinatario del pasado, mostramos cómo estos lugares de memoria son interpretados en una lógica más bien privatizada y ghettizada. Conscientes de que la experiencia cívica puede ser un importante terreno para la construcción de formas de ciudadanía capaces de ensanchar la explicación del pasado, mediante un conjunto de nuevos repertorios simbólicos y narraciones colectivas que pueden transformarse en un recurso extraordinario para la acción política, concluimos que las memorias juveniles presentan una débil condición pública, lo que permite arriesgar ciertas hipótesis acerca del tipo de socialización política en la que se han formado: una que en cierta medida ha acrecentado la despolitización, dificultando una relación virtuosa entre memoria y ciudadanía.

\section{MARCO TEÓRICO}

\section{Memorias sociales y pasados de violencia politica}

Desde que a inicios de los años setenta la memoria se constituyera en un campo de estudio en las ciencias sociales (Traverso, 2007), los estudios enmarcados desde una

4. El DDEP, ubicado en el Cementerio General, junto con conmemorar a las víctimas de la represión política, opera como lugar de entierro. Fue inaugurado el 26 de febrero de 1994, realizado por iniciativa de la Agrupación de Familiares de Detenidos Desaparecidos y Agrupación de Familiares de Ejecutados Políticos, y financiado por el Ministerio del Interior. El monumento a las Mujeres Víctimas de la Represión, MM, inaugurado el 12 de diciembre de 2008, se ubica en el bandejón central de la avenida Bernardo O’Higgins, sobre la estación de metro Los Héroes en la comuna de Santiago. El propósito del Comité Pro Monumento a las Mujeres Víctimas de la Represión, fue situar en el espacio público a las mujeres que fueron víctimas directas de la dictadura (Ministerio del Interior, 2010). 
tradición social de la memoria (Ricoeur, 2003) no han dejado de producirse, enfatizando que las interpretaciones compartidas del pasado, particularmente cuando se trata de un acontecimiento histórico conmovedor o traumático, constituyen un componente esencial de la identidad colectiva. Es en esta tradición donde nos situamos, entendiendo que la memoria social es una "narración que media» los sistemas heredados de creencias, prácticas y tradiciones, que van dando forma a un marco interpretativo que permite comprender la acción colectiva y el estado de la cultura política de un grupo social (Wertsch, 2002).

Asumimos que recordar no es un proceso que trae y desplaza lo ya acontecido hacia el presente, sino más bien una operación donde el pasado es reconstruido en función de los intereses, convenciones, valores, principios, ideas y afectos que son parte de las dinámicas y prácticas presentes llevadas a cabo por los grupos sociales (Halbwachs, 2004). Es por esa razón que, pese a contar con una amplia evidencia sobre cómo transitan las memorias sociales de una generación a otra (Mannheim, 1993; Jelin, 2002; Le Quintrec y Geiss, 2006) los especialistas suelen insistir en que el pasado es siempre algo precario y modificable, que no siempre conserva su intensidad emocional y su influencia política.

Cuando se trata de sociedades que han experimentado la violencia política, la aparición del debate sobre la memoria colectiva depende de la interacción de varios factores, como el grado de libertad del régimen político para permitir su voz y su difusión, la magnitud del trauma o del evento, la naturaleza de la transición política de un régimen a otro o las estrategias empleadas en los primeros años después de la transición. Muchos países que experimentaron un pasado traumático afrontaron el problema de la memoria y el enjuiciamiento del pasado solamente durante un primer periodo de la transición a la democracia, que luego fue seguido por un período «institucionalizado» de silencio (Judt, 2010), donde la mayoría de las acciones se centraron en el enjuiciamiento de actos criminales concretos y demostrables, en contraposición al debate sobre cuestiones más amplias relacionadas con la culpabilidad social. Como sugiere un estudio ya clásico (Sa'adah, 1998), no es poco común que después de un episodio traumático causado por un régimen inescrupuloso, como de hecho ha sucedido en Chile y en el Cono Sur de América Latina durante los ochenta (Reyes et al., 2015), algunas democracias inicialmente persigan instaurar un debate minimalista sobre su memoria reciente, encaminado a restablecer la confianza en el nuevo proceso político.

\section{Transmisión de memorias de violencia politica: dialogía, nuevas generaciones $y$ lugares de memoria}

Uno de los procesos de mayor relevancia en la configuración de las memorias sociales es el de la transmisión intergeneracional. Como hemos sistematizado en otro lugar (Reyes et al., 2015), para el caso de Chile, transcurridas algo más de dos décadas de gobiernos postdictatoriales y produciéndose el «relevo generacional» (Aguilar, 
1996), después de las primeras investigaciones y reflexiones centradas en las disputas colectivas y en el asentamiento de memorias emblemáticas de la Dictadura Militar, se ha comenzado a estudiar los espacios y prácticas sociales que actúan como «vehículos de memoria» (Jelin y Langland, 2003). Los distintos trabajos realizados desde este prisma, suelen atender a los «emprendedores de la memoria» (Jelin, 2002) y las acciones que llevan a cabo para instalar públicamente un sentido del pasado específico. Si bien las nuevas generaciones en la literatura internacional han comenzado a ser analizadas en tanto "destinatarias» de la transmisión, considerando a sus memorias como «vicarias» (Young, 2000a), mediatizadas (Sarlo, 2007; Struken, 2008) o bien como "postmemoria» (Hirsch, 2008), solo en los últimos años se les ha indagado en Chile (Juárez y Salanova, 2009; Sepúlveda et al., 2015; Piper, 2015). Con todo, aún es marginal en dichos análisis la reflexión respecto a la transmisión que en términos dialógicos se produce entre las nuevas generaciones y las generaciones protagonistas, así como las subjetividades políticas que se generan en el marco de estos procesos.

$\mathrm{Si}$ asumimos la memoria como una práctica social, como un proceso intersubjetivo continuo, contingente y contextual (Middleton y Edwards, 1990; Vázquez, 2001, 2002), cobra sentido abordar las configuraciones de memorias desde una perspectiva dialógica, pues lo que se recuerda y olvida es una construcción que se produce en un espacio relacional, de manera que lo que una posición afirma, sostiene o interroga, es siempre una respuesta a otra posición (Reyes et al., 2015).

Durante las transiciones políticas, los «emprendedores de la memoria», así como los actores político-institucionales, realizan una serie de acciones con el propósito de transmitir particulares versiones del pasado, siendo una de las principales la construcción de lugares de memoria (Jelin y Langland, 2003). En el caso de Chile, la construcción de memoriales y monumentos cobró relevancia como respuesta a las medidas de reparación propuestas por la Comisión Nacional sobre Prisión Política y Tortura (2005), constituyéndose en un gesto simbólico de reconocimiento y encuentro social, dirigido «a la reparación moral y a establecer condiciones en la sociedad para que no se repitan hechos de esta naturaleza» (Comisión Nacional sobre Prisión Política y Tortura, 2005: 521).

En este marco, los lugares de memoria pretenden instituir un particular sentido del pasado, trascendiendo y permaneciendo en y a través del tiempo. Como dirá Candau (1998), es una materialización que tiene la vocación de «fijar» el pasado, constituyendo "una memoria 'educada', incluso 'institucional' y por lo tanto compartida" (Candau, 1998: 115). En este sentido, los lugares de memoria hablan de los acontecimientos y significados construidos en el tiempo, así como del uso y desuso del pasado y su pregnancia en el presente (Rilla, 2009). Por tanto, por más que se intente fijar una versión del pasado, «los procesos de construcción de memorias son siempre abiertos y nunca acabados» (Raposo, 2009: 180). Es más, «solo un proceso memorial inconcluso es capaz de garantizar la vida de la memoria» (Young, 2000b: 80).

La investigación social sobre los lugares de memoria en el caso chileno, en particular de monumentos y memoriales, se ha centrado en los procesos de su construcción (Hite, 2003, 2013), en las prácticas y usos de actores sociales específicos en dichos espacios (Piper et al., 2009; Sepúlveda et al., 2015), en el potencial que implica para 
el aprendizaje el visitarlos (Toledo et al., 2006), así como en las distintas narraciones que se inscriben en ellos (Lazzara, 2003). Si bien todas estas investigaciones realzan la centralidad del proceso de transmisión, resta aún abordar la interpelación que realizan los lugares de memoria en tanto «lugares de enunciación» (Jelin y Langland, 2003) a las nuevas generaciones, así como la construcción de memorias que desde esta dialogía se produce, cuestión que nos permite indagar en los diversos efectos políticos que se están inscribiendo en las subjetividades juveniles.

\section{Subjetividad politica juvenil y construcción de memorias}

Si la política involucra un proceso mediante el cual el sujeto, consciente de su particularidad, cuestiona el orden impuesto y su relación con los otros, y desde este reconocimiento participa en el mundo, sugerimos que el sujeto se hace presente en el mundo a través de un proceso de significación. Ello porque las condiciones que permiten la presencia de un sujeto provienen de su inserción semiótica y material en un contexto normativo de reglas que regulan las prácticas que establecen lo que debe y no debe hacer, pues la acción política ha de entenderse desde una lógica dual, en tanto que se presenta escindida en un doble movimiento, «en la tensión (y ruptura) entre 'lo posible' (como reconocimiento de la relación necesidad-contingencia) y 'lo imposible' de un acto de fuerza que pretende instaurar una norma para la que no existe un fundamento último» (Ema, 2004: 4).

Así, el proceso de subjetivación mismo responde a la formación de un uno que no es un sí, sino la relación de un sí con otro (Rancière, 1996: 21), en tanto que la subjetividad es aquella constante redefinición del status mismo del sujeto, el que se constituye a partir de su relación diferencial respecto del orden social a partir del disenso. De ahí que la lógica de la subjetivación política se constituya en una heterología; en una lógica del otro estrechamente asociada a un proyecto de emancipación en el que «el individuo se convierte en actor para fabricarse como sujeto" (Martuccelli, 2007: 25).

No podemos pensar en el sujeto como origen de la acción (política) sino que debemos pensarlo desde la acción misma, ya que la producción del efecto es parte de la constitución de lo que retroactivamente se considerará como su antecedente "causal», el sujeto, porque preguntarse por el modo cómo se produce el sujeto de la política (como efecto de la propia acción política) sitúa la cuestión del sujeto en el terreno de lo político, en el terreno de lo controvertido, de la historicidad y la contingencia (Ema, 2004). El sujeto no es el antecedente racional, autónomo y transparente de la acción, sino que se crea en ella, como marco de sentido; como un «entredós que se teje y diseña entre ambos» (Martuccelli, 2007: 17).

Desde que Norbert Lechner (2002) insinuara que la socialización política de los jóvenes chilenos del nuevo siglo debiera articularse en procesos que permitieran desplegar su subjetividad política, orientando los comportamientos y prácticas en torno a concepciones fuertes de equidad y justicia social, los estudios sobre cultura política juvenil se han ocupado de aspectos ciudadanos relacionados con el voluntariado, la 
acción colectiva y la movilización estudiantil (Hatibovic et al., 2012). También, desde la incidencia que tienen los proyectos individuales de los jóvenes en lo político se les ha analizado como sujetos a partir de los cuales se pueden revelar las transformaciones estructurales y subjetivas por las que atraviesa la sociedad chilena, a partir sobre todo de las nuevas formas de organización que les separan de 'lo tradicional' y les generan identidad (Reguillo, 2003; García Agustín y Aguirre, 2014).

Aunque la mayoría de los jóvenes comienzan a dar forma a sus recuerdos con la ayuda de su entorno familiar, la importancia de la socialización política secundaria en la fijación de normas y valores es cada vez mayor y ha sido prolijamente estudiada (Almond y Verba, 1963; Tilly, 1992; Snow y Benford, 1992; Aguilar, 1996).

En este trabajo exploramos la subjetividad juvenil frente a diversas formas de materializar la memoria social, en el sentido de que los jóvenes tienen valoraciones racionales sobre lo justo y lo injusto, así como percepciones claras sobre los espacios sociales de inclusión y exclusión. Es por este motivo que la expresión de un relato juvenil sobre la memoria adquiere una condición pública solo en la medida en que es relevante en el proceso formativo de su propia subjetividad política, en tanto permite a cada individuo ubicarse en una esfera de lo público, a partir de la que puede describirse ese «sentido común» que resume la pluralidad de intereses, pensamientos y voluntades de acción de un grupo social (Radstone, 2008), es decir, en espacios de expresión (ahora pública) que interpelan sobre lo sucedido, muchas veces frente a la indiferencia y el rechazo social.

Sabemos que las memorias colectivas afectan decisivamente los imaginarios y las representaciones de la cultura política, limitando los sistemas de creencias, las prácticas sociales, las tradiciones heredadas y, muy especialmente, los valores que proporcionan la identidad de un grupo social. Esto implica que aunque exista una amplia evidencia de la transferencia intergeneracional del trauma y de la memoria $(\mathrm{McDowel}$ y Braniff, 2014), las memorias colectivas no siempre conservan su intensidad emocional y su influencia política. De ahí que la infraestructura, los lugares, la documentación, las conmemoraciones y la pervivencia de organizaciones de la sociedad civil dedicadas a mantener la memoria viva, constituyan un factor que facilita la longevidad y la recreación de la memoria y su influencia en la respuesta institucional y en los comportamientos generados por los acontecimientos históricos y los recuerdos mismos. En ese sentido, los resultados que más adelante presentamos, nos permiten interpretar ciertas hipótesis acerca de cómo ha operado la socialización política de los jóvenes a propósito de los lugares de memoria.

\section{NOTA METODOLÓGICA}

El universo empírico de esta investigación lo conforman, de un lado, lugares de memoria que se emplazan en la Región Metropolitana de Santiago de Chile, y que tienen por objeto recordar el pasado reciente de violencia y represión política vivida en el país; de otro, una generación de jóvenes residentes en la mencionada región, que crecieron en los últimos años de la dictadura militar y los primeros de la actual demo- 
cracia, y que responden a distintos tipos de orientación político-ideológica en sus familias de origen. Ninguno de ellos conocía los lugares de memoria seleccionados.

Entenderemos que los jóvenes que visitaron los lugares son parte de una «generación sucesora» (Reyes, 2009) a propósito de las formas en que han operado los procesos de transmisión intergeneracional de las memorias sociales de la dictadura.

Trabajamos con un muestreo no probabilístico, de tipo intencionado y orientado por criterios teóricos, combinado con el de accesibilidad y factibilidad según los recursos disponibles. Tratándose de un estudio exploratorio, se hizo una selección estratégica según las pautas de un determinado muestreo teórico que genera un esquema conceptual general, coherente con el ordenamiento de determinadas variables, que en este caso corresponden a: formas estéticas de los lugares de memoria -abstracta y concreta-, en el sentido que estas condicionan los discursos que se configuran desde quienes circulan y/o habitan dichos lugares (Juárez y Salanova, 2009); y jóvenes de familias con distintas posiciones ideológicas -izquierda y derecha-, en la medida que la investigación ha mostrado su centralidad en la producción de sentidos sobre el pasado (Cornejo et al., 2013).

La submuestra que aquí utilizamos, se compone de dos casos (lugares de memoria) que se diferencian por su estética. Así, se trabajó con un lugar más abstracto -el MMy otro más concreto -el DDEP.

IMAGEN 1.

Monumento Mujeres en la Memoria

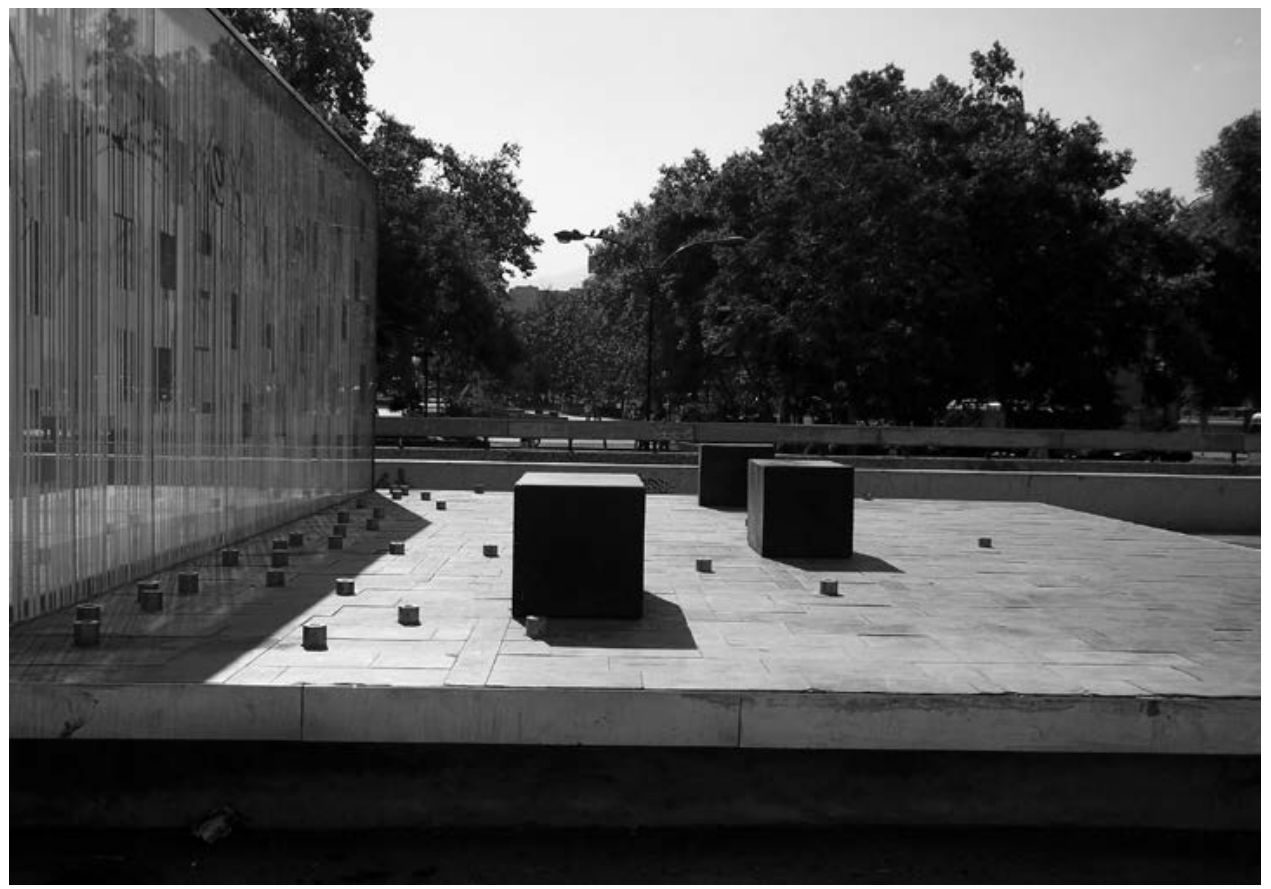

Fuente: fotografía realizada por joven participante del estudio. 
IMAGEN 2.

Memorial del Detenido Desaparecido y del Ejecutado Político

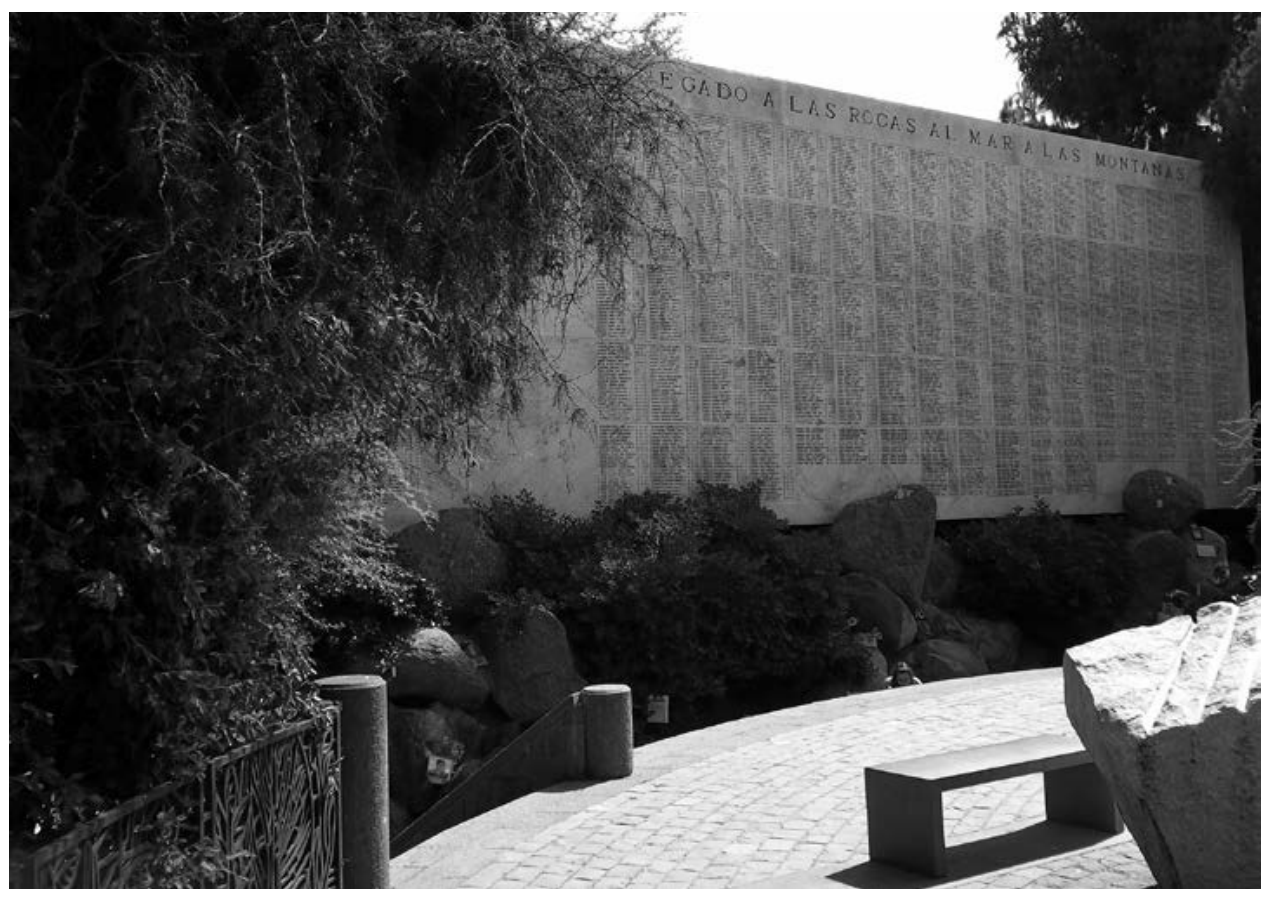

Fuente: fotografía realizada por joven participante del estudio.

Cada uno de ellos fue visitado por cuatro jóvenes, dos provenientes de familias con una posición política de izquierda y dos de derecha:

TABLA 1.

DiseÑo MUESTRAL

\begin{tabular}{lcc}
\hline & $\begin{array}{c}\text { Lugar de memoria con } \\
\text { forma estética abstracta: } \\
\boldsymbol{M M}\end{array}$ & $\begin{array}{c}\text { Lugar de memoria con } \\
\text { forma estética concreta: } \\
\boldsymbol{D D E P}\end{array}$ \\
\hline Joven de familia de izquierda & 2 & 2 \\
\hline Joven de familia de derecha & 2 & 2 \\
\hline Total de jóvenes que visitaron cada lugar & 4 & 4 \\
\hline
\end{tabular}

Total de casos: 2 lugares de memoria; total de jóvenes: 8; total de visitas a los lugares de memoria: 2, una a cada lugar; total de entrevistas grupales: 2, una para cada lugar.

Fuente: elaboración propia. 
El diseño metodológico se estructuró en cinco etapas: a) una revisión documental nos permitió seleccionar los lugares de memoria, a partir de los objetivos y el mensaje que se esperaba transmitir a través de las formas estéticas y simbólicas que les daban forma; b) visitas preliminares a los lugares de memoria por parte de los investigadores y notas de campo, que permitieron elaborar un registro detallado del emplazamiento y de la estética de cada lugar; c) visita de jóvenes al lugar de memoria donde se les solicitó, tras un recorrido libre, que fotografiaran aquello que llamara su atención y les pareciera significativo, escogiendo posteriormente hasta cinco imágenes que serían utilizadas en la siguiente etapa del estudio, en tanto que los investigadores pusieron en práctica la técnica de la observación para registrar la actividad; d) una entrevista grupal que se realizó después de la visita que permitió, a partir del registro fotográfico, identificar cómo interpretaban los sujetos la dimensión enunciativa del lugar y describir los diferentes relatos del pasado que se generaron, y e) finalmente se procedió a analizar todo el material a la luz de la técnica del análisis del discurso, fijando nuestra atención en la identificación de las posiciones de habla de los sujetos, el análisis de las formas retóricas del discurso y sus consecuencias, así como en la forma de la construcción narrativa del discurso y en las tensiones discursivas que se producían. Aquí nos basamos solo en la dimensión narrativa de la entrevista grupal, excluyendo el análisis de las fotografías.

La estrategia analítica supuso - primero- transcribir las conversaciones de los tres grupos (aunque aquí presentamos los dos más extremos según el tipo de memoriales), para -segundo- codificar los temas y subtemas de cada conversación (Coffey y Atkinson, 2005). Ello permitió ordenar los tópicos de cada grupo y luego establecer un análisis transversal entre ellos. En un tercer momento se procedió a analizar cada conversación grupal desde la lógica del análisis de discurso (Iñiguez y Antaki, 1998), basado en identificar el sentido que tienen las acciones para los sujetos, para luego proceder a lo que Canales (2013) recomienda como "escucha crítica» del habla, la cual vincula el sentido que tiene el habla para los actores con sus posiciones en la estructura de relaciones sociales en las que participan. Esta última etapa implica un análisis más interpretativo que se nutre, además, del análisis previo, tanto del conocimiento del contexto social del estudio como de la experticia acumulada en nuestras investigaciones previas en este campo (Reyes et al., 2015; Reyes et al., 2013; Cornejo et al., 2013; García y Aguirre, 2014; Cruz, 2004). De todos los resultados del estudio hemos seleccionado para este artículo lo relativo a las posiciones discursivas (quién y para quién se transmite a través de los lugares) y los sentidos del pasado (qué y cómo se transmite), junto con la interpretación más teórica y crítica que hacemos desde los desafíos que lo anterior supone en materia de socialización política.

\section{RESULTADOS}

\section{El quién de la transmisión: el emprendedor de memoria, el joven y el destinatario}

La construcción intencionada de lugares de memoria tiene por finalidad trascender al tiempo, inscribiendo una versión del pasado a través de las particulares formas 
estéticas que adopta. De este modo, se genera una dimensión enunciativa del lugar, que habla o invita a hablar de las relaciones sociales que lo han constituido, así como de aquello que se pretende transmitir. Naturalmente que esta dimensión enunciativa requiere de una interpretación, pues «los sentidos nunca están cristalizados o inscriptos en la piedra del monumento o en el texto grabado en la placa. Como 'vehículo de memoria', la marca territorial no es más que un soporte, lleno de ambigüedades, para el trabajo subjetivo y para la acción colectiva, política y simbólica, de actores específicos en escenarios y coyunturas dadas» (Jelin y Langland, 2003:4).

En nuestro caso, esta interpretación no la entendemos como propiedad de un actor sino más bien como discursos que son resultado de un proceso dialógico entre el joven y el lugar, que en su despliegue dan cuenta de particulares sujetos, objetos y relaciones. En el caso de los lugares seleccionados, la enunciación de los jóvenes implica la emergencia de un discurso que evidencia un quién, que ha tenido la intención de transmitir una particular versión del pasado, vale decir, los «emprendedores de memoria» (Jelin, 2002). Ese quién se caracteriza por ser un colectivo inscrito y significado, en el caso del memorial del DDEP, como un familiar de las víctimas de la represión política estatal, mientras que en el caso del monumento de MM, se trata de mujeres «que quieren dejar algo, que quieren que las recuerden»:

[...] bueno, yo cuando entré, lo primero que me llamó la atención fue que me senté en un banquito y al frente había una lápida que decía «¿dónde están?». Entonces eso inmediatamente te remite a las campañas de los familiares de detenidos desaparecidos (entrevista grupal DDEP).

[...] a mí se me imagina que las mujeres igual fueron parte un poco, con el artista, de manifestar un poco una historia, ellas son las que quieren dejar algo, que quieren que las recuerden yo creo que ese es el tema, que no tiene que ver con un monumento y tiene que ver con un recuerdo que dejan a las otras personas que quieren ellas (entrevista grupal MM).

Junto a los emprendedores se articula el lugar del joven, principalmente a través de dos claves. Por un lado, como «no protagonista» del pasado reciente, lo que trae aparejado la dificultad de sostener ante otros -sean de la propia generación o bien de otra- su posición respecto a lo "ya acontecido». En sus palabras, «si tu no lo viviste [...] no sabes nada de lo que pasó». Por otro lado, constantemente emerge la referencia al hecho de ser familiar o no de quien fue reprimido y violentado políticamente como la única posición que puede legítimamente referirse y posicionarse ante el pasado reciente.

Siempre me ha llamado la atención porque siempre lo he escuchado en jóvenes:

-Oye, cómo es posible, el tema es por qué hablas pestes y criticas esto si pasó hace tanto tiempo.

-Si tú no lo viviste.

-Si tú no lo viviste claro, no sabes nada de lo que pasó. 
Pero resulta que yo no viví esto pero mis padres sí, mi abuelo sí y como que la juventud o en general las personas tratan de olvidarse de eso, pero como que se ha creado la conciencia de que anda sigue para adelante, pero no mires atrás y uno como ser humano crea su identidad en base a su situación familiar [...]. La juventud dice eso, pero igual incluyo un poco a los adultos, también por lo mismo, porque ellos sienten como que es su propiedad, como que no tú no sabes nada (entrevista grupal MM).

Desde la dialogía que se produce entre el joven y el lugar de memoria se constituye, a su vez, un destinatario de la versión del pasado que se quiere transmitir: a pesar que se declara que los lugares de memoria son y debiesen ser destinados a la sociedad en su conjunto, apuntando con ello a un "deber de memoria», el principal destinatario que emerge es el "familiar de las víctimas de represión política». En el caso del memorial del DDEP, ello se evidencia al constituirse como espacio donde es posible recordar a los familiares a través de gestos y ritos propios de nuestra cultura -flores, fotografías, mensajes-. Mientras que en el monumento MM, al imaginar que quienes son llamados a visitar el lugar son aquellos que de algún modo se encuentran vinculados al mensaje que se quiere transmitir:

A mí la sensación que me dio a veces era como de ocultar un poco, el que solamente las personas que estaban conectadas con, con la idea de los detenidos desaparecidos podrían detenerse, y mirarlo y apreciarlo y quedarse ahí, pero una persona que no estuviera conectada es como que queda ahí tapado por los árboles, por las esculturas 'ah qué bonito' y no pasaría nada (entrevista grupal DDEP).

[...] es como una construcción que tiene un significado para las personas que está hecha para quien la hizo, para quién la diseño, pero no sé si para la gente que lo visite [...] o sea en nombre de las cuales se hizo el memorial, yo creo que es mucho más significativo para ellas; para uno como persona como ciudadano como visitantes de ese lugar, no sé si tanto (entrevista grupal MM).

Lo anterior pone en tela de juicio la capacidad de estos lugares de activar procesos de transmisión de la memoria más allá de quienes vivieron más directamente la represión política. Una vez más, el deber de memoria queda circunscrito a los lazos familiares de las víctimas directas. Para los jóvenes, solo quienes ya están conectados con el tema de las violaciones a los derechos humanos podrían detenerse, con lo cual volvemos al tema del uso del lugar, que quedaría en una suerte de guetto (Jara, 2013) solo para los familiares o quienes ya están sensibilizados frente al tema de la represión política, impidiendo una memoria más formativa y ampliada al resto de la ciudadanía, lo que disminuiría incluso la eficacia del memorial como lugar de visibilidad, en tanto más allá de tildarlo como un "lugar bonito» no tiene mayores impactos. En términos de pragmática del discurso no estamos solo frente a una descripción del lugar, sino ante un reclamo. 


\section{El qué y el cómo del proceso dialógico de transmisión}

En términos generales, el qué se transmite desde el lugar de memoria y se circunscribe temporalmente al pasado reciente -la dictadura militar-. En el caso del memorial del DDEP, la dictadura se hace presente principalmente por la figura del «detenido desaparecido» -no así el del ejecutado político-, la que se materializa a través del listado de nombres inscritos en los muros y en los nichos. No obstante, se trata de un "detenido desaparecido» que es significado principalmente como «familiar». Es el abuelo o abuela, padre o madre, hijo o hija, cuestión que se sostendría por tres razones principalmente: por un lado, el emplazamiento del memorial en el Cementerio General, lugar donde principalmente se recuerda a familiares; por otro, los mensajes que dejan quienes visitan el lugar, donde se explicita claramente que el destinatario es un familiar; por último, por el uso dado al lugar, donde los rastros -flores, velas, mensajes y fotografías- adquieren significado como un acto de recuerdo hacia quien es parte de la propia familia:

Yo pienso que si me pongo en el lugar de una persona que es familiar de detenidos desaparecidos y no sabe dónde está su hijo, o pienso que uno el mayor consuelo que tiene al perder un ser querido es poder ir a verlo, poder dejarle flores, saber dónde está esa persona y tener un poco dignidad de poder enterrarlo [...], ese memorial da como especie de eso, de querer que la gente entregue sus sentimientos o deposite lo que siempre ha querido tener, como de su cultura para su ser amado y el Gobierno no dejó po..., no, simplemente no saben dónde están y tienen que acudir a un memorial (...) ir a entregar su pena, su angustia, es como una especie de desahogo por decirlo así (entrevista grupal DDEP).

En el caso del monumento MM, las claves que permiten a los jóvenes situarlo en el pasado reciente son, por una parte, la invitación que realiza el equipo de investigación a visitar este lugar en tanto lugar de memoria. Por otro, la placa que explicita que se trata de un monumento en conmemoración a las mujeres que fueron víctimas de la represión política. A pesar que los jóvenes expresan que el monumento «no está ahí porque sí», dada su estética más bien abstracta, es un monumento que no habla por sí mismo, que no interrumpe la cotidianeidad con su presencia. El muro transparente, las luces, el cemento, los grafitis y rayados, su emplazamiento - pleno centro de Santiago-, la dificultad en acceder a él, así como la falta de cuidado y de mantención que se evidencia, no solo instalan pocas claves de lectura para la transmisión de las versiones del pasado materializadas en el monumento, sino que a la vez genera tensiones respecto al lugar que se le otorga a la memoria de las mujeres en nuestro presente. Es así como se habla de "falta de respeto», «invisibilización de las memorias y de las mujeres» e incluso de un monumento realizado más por «deber» que por otra cosa: el monumento muestra una suerte de desmemoria o voluntad de no recordar el pasado; es decir, opera como metáfora para apuntar a que «no tenemos la capacidad de ver lo que pasa» (entrevista grupal MM). 
[...] como que en verdad da lo mismo, como que el lugar que tiene un monumento como todas cosas (públicas) mandan hacer un monumento y como que no es personal, como que había que hacer algo y lo hicieron (entrevista grupal MM).

A pesar que el Memorial del DDEP entrega más claves de lectura, también su emplazamiento y estética provoca algo similar a lo que apreciamos en el Monumento MM, pues tiende a ocultar el pasado; en palabras de los jóvenes, "quien no esté conectado con los detenidos desaparecidos es como que queda ahi tapado por los árboles, por las esculturas 'ah que bonito', y no pasaría nada» (entrevista grupal DDEP). En este sentido, ninguno de los lugares de memoria -aún más en el caso del Monumento MMlogra «convocar» a otros. Si bien el Memorial del DDEP posibilita que los jóvenes se «conmuevan» y «empaticen» con el dolor y el sufrimiento, en la medida que sitúan a quienes son conmemorados como "personas" que son parte de una "familia», igualmente llama poco a la detención y menos aún a dialogar con la versión del pasado que ahí se propone, tanto más cuanto la capacidad de convocar no está en el lugar sino en la motivación de quienes podrían interesarse en él.

\section{Algunos efectos politicos de la dialogía entre los lugares de memoria y las generaciones} sucesoras: las memorias privatizadas y despolitizadas

Reflexionar sobre el pasado reciente en clave de memoria social supone aceptar que no hay una sola memoria sino varias, y que se trata siempre de disputas entre versiones hegemónicas y subalternas. Entender los procesos de transmisión del pasado de manera dialógica también implica aceptar que no hay emisores que entregan un legado cerrado ni jóvenes receptores pasivos que solo lo rechazan o reproducen, sino una relación en la cual lo que se rememora cambia constantemente y se resignifica de diferentes formas. Sin embargo, desde la perspectiva de investigadores comprometidos con ciertas memorias y no con todas, nos preguntamos por los riesgos que supone lo que hemos mostrado hasta ahora, no tanto desde el debate sobre los lugares de memoria, sino a partir de la pregunta por la socialización política de los jóvenes actuales.

Para ello hay que recordar lo que indicamos en el marco teórico. Por una parte, que las interpretaciones compartidas del pasado son componentes esenciales de la identidad colectiva y de la cultura política de los grupos sociales, y que los sentidos que otorgamos al pasado están en permanente transformación, por lo que ese pasado es sensible a las respuestas institucionales pensadas para significar los acontecimientos históricos. A su vez, quienes participan en las disputas por dar sentido al pasado no solo resultan cruciales para la difusión y la defensa de determinadas memorias, sino que también se erigen en agentes de socialización privilegiados en la formación ciudadana de los jóvenes, pues hay que recordar que los lugares de memoria tienen como objetivo interpelar a la sociedad en su conjunto. Sin embargo, el proceso dialógico entre los jóvenes y los lugares genera como efecto un particular destinatario: los familiares de las víctimas de la represión política. Son ellos los que pueden comprender y 
sentirse llamados por estos lugares; son ellos los que les dan vida. En este sentido, las versiones del pasado que se transmiten desde estos lugares de memoria interpelarían a unos pocos -los familiares-, "privando" a otros -en este caso, jóvenes no familiaresde apropiarse e interrogarse a partir del pasado reciente de Chile.

A pesar de esta privatización, se va constituyendo en la relación dialógica una particular memoria del pasado reciente. Se habla de, por ejemplo, «personas desaparecidas», de «represión», de "dictadura», de "ambos lados», pero no desde una narración de acontecimientos y personajes, sino más bien con palabras que dimensionan una memoria que no propicia el debate ni la controversia; se trata de una memoria que no es politizada (Reyes et al., 2013).

Los énfasis en la familiarización de la memoria y su privatización hace que las memorias del pasado reciente silencien también las marcas políticas de quienes fueron objeto de la represión durante la dictadura: los «desaparecidos», esas "mujeres», no son vistos como agentes con capacidad de acción, con proyectos políticos o con historia propia. Una forma de significarlos que enlaza además con la consigna de la «paz». Los jóvenes saben que se está haciendo referencia a los detenidos desaparecidos -la forma más reiterada con que se los nombra en Chile-, pero los resignifican desde un logo distinto que se repite en varios momentos de la conversación; no son combatientes, ni militantes; tampoco víctimas. Son "personas desaparecidas», tal como lo muestra este fragmento:

- A mí me gustó mucho el lugar, sobre todo ver que todavía la gente recuerda a esas personas que desaparecieron y que se vean como las flores, que están bien cuidadas. También impactante como las frases que habían, había una del Che, que le saqué una foto, que es muy buena. También me gustó como, esa como gran muralla con todos los nombres, que fue como impactante la cantidad de personas que desaparecieron, el dolor, y sobre todo esas como cuatro caras que eran como piedras (ver imagen 3), que reflejaban mucho como se podría decir el ambiente del lugar. Que es como, como que muestra mucho, pero... no es como ni una sonrisa ni una cara como de pena, como normal, como que lograron la paz, como reencontrarse con ellos mismos, como relajados, como dormidos. Por eso me gustó mucho.

- Cuando dices esto del ambiente del lugar, que se refleja en el ambiente, ¿a qué te refieres?

- Como tranquilidad, como que ya terminó la dictadura, el golpe, todo y lograron como la tranquilidad que buscaban, yo creo. Como la familia, poder compartir con esas personas» (entrevista grupal DDEP).

Esta despolitización de las «personas» desaparecidas, expresada en clave familiar y voluntarista («paz»), nos permite hipotetizar que estos jóvenes han participado (como destinatarios y resignificadores) de determinadas versiones del pasado y de particulares formas de socialización política que acentúan la lógica de la «reconciliación nacional», como una narrativa oficial que encapsula las formas de procesar el pasado reciente (Cruz, 2004); un tipo de socialización política huérfana de políticas públicas-como las políticas de reparación o las políticas educacionales referidas a la enseñanza del pasado reciente- y nutrida, más bien, de repertorios familiares (Cornejo et al., 2013). 
IMAGEN 3.

Esculturas en Memorial del Detenido Desaparecido y del Ejecutado Político

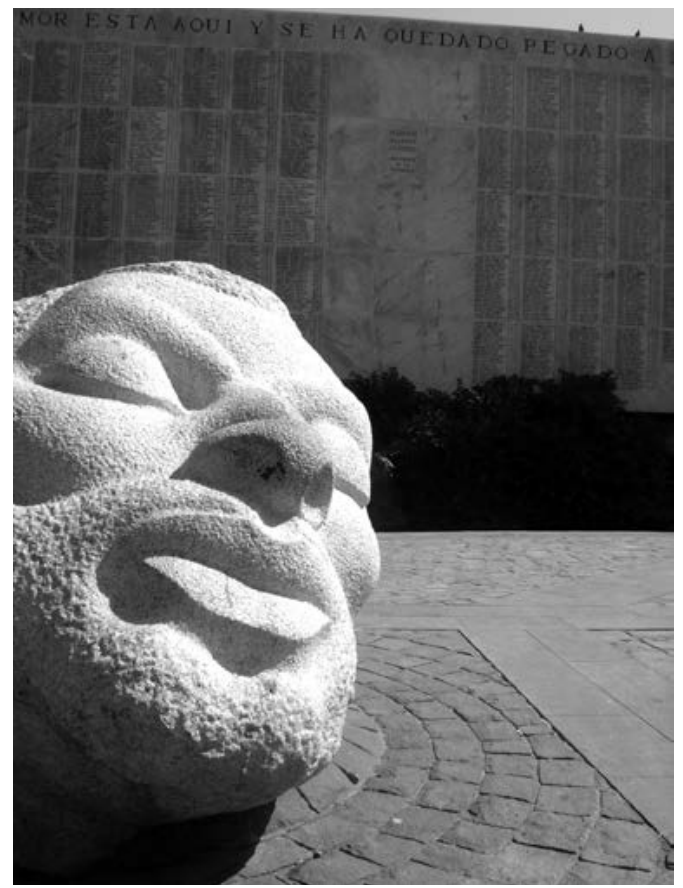

Fuente: fotografía realizada por joven participante del estudio.

\section{CONCLUSIONES: UNA SOCIALIZACIÓN POLÍTICA QUE DESPOLITIZA}

Los entrevistados se expresan como espectadores de memorias en juego que no remiten a claves públicas, sino privadas. Se puede entonces concluir que la socialización política en la que han sido formados contempla una memoria del pasado que sugiere que lo acontecido en dictadura es un asunto privatizado -de los "familiares» de las «víctimas» o «las mujeres víctimas»-, lo que parece impedir que los jóvenes encuentren un lugar legítimo para posicionarse, interpelar o solidarizarse con respecto al pasado.

$\mathrm{Si}$ al menos en términos temporales el foco de las memorias desplegadas son «los tiempos de la dictadura militar», los memoriales no provocan en estos jóvenes hablar ni del pasado previo (la Unidad Popular por ejemplo) ni del tiempo de la postdictadura. No hay tramas históricas, no hay un antes y un después, es un período casi descolgado de la historia, una suerte de paréntesis. En el caso del memorial del DDEP, el pasado de la dictadura se hace presente principalmente por la figura del «detenido desaparecido»-significado principalmente como «familiar»-. Para el caso del monumento MM, surge el tema de su «invisibilización» y la desconfianza hacia el memorial. 
Si a ello sumamos la constatación de que el memorial del DDEP presenta un emplazamiento y una estética que tienden a "ocultar el pasado", ambos lugares de memoria no solo no logran "convocar» a otros, sino que terminan por ocultar el pasado. Nuevamente lo que los jóvenes interpretan de estos memoriales se reduce a la lógica privatizada y guetizada del sufrimiento de familiares de las víctimas de la represión.

Como insinuamos en el ensamblaje teórico, podemos argüir que las memorias del pasado que activan estos lugares no pueden adquirir una condición pública, en tanto no resultan relevantes para el proceso formativo de la subjetividad política. Por el contrario, los lugares impiden que cada joven se ubique en una esfera de lo público a partir de la cual puedan abrirse a ese "sentido común» que apela a la pluralidad de intereses, pensamientos y voluntades de acción política. Se ha argumentado que las políticas de memoria pueden ser compatibles con los ideales asociados a la ciudadanía cuando, a través de los discursos memorísticos, se logran actualizar los derechos de ciudadanía, tanto en su sentido procedimental como sustantivo, o cuando se consigue reconfigurar tales derechos en aras de promover el ideal de la no-dominación, en situaciones donde la ciudadanía no se cumple o en nuevos ámbitos que considerar (Monsiváis, 2008: 62).

El caso que presentamos muestra lo contrario. Al recordar que la relación entre memoria y ciudadanía no necesariamente es virtuosa, sino un vínculo sujeto a la contingencia, pareciera que estamos frente a un tipo de socialización política que habría acrecentado la despolitización: frente a jóvenes espectadores que se conmueven con el dolor de algún familiar de un detenido desaparecido, que se solidarizan con alguna memoria privada y que asumen el memorial como otra forma de silenciar el pasado reciente, como otra excusa para apuntalar la desmemoria.

\section{Referencias}

Aguilar, Paloma. 1996. Memoria y olvido de la Guerra Civil española. Madrid: Alianza Editorial.

Aldmond, Gabriel y Sidney Verba. 1963. The civil culture. Political attitudes and democracy in five nations. California: Sage Publications.

Coffey, Amanda y Paul Atkinson. 2005. Encontrar el sentido a los datos cualitativos. Estrategias complementarias de investigación. Alicante: Universidad de Alicante.

Canales, Manuel (coord.). 2013. Análisis e interpretación en la investigación cualitativa. Santiago: Lom.

Candau, Joel. 1998. Memoria e identidad. Buenos Aires: Del Sol.

Comisión Nacional sobre Prisión Política y Tortura. 2005. Informe de la Comisión Nacional sobre Prisión Politica y Tortura. Santiago: Ministerio del Interior.

Cornejo, Marcela; María José Reyes; María Angélica Cruz; Nicolás Villarroel; Anastasia Vivanco; Enzo Cáceres y Carolina Rocha. 2013. «Historias de la Dictadura Militar desde voces generacionales», Psykhe, 22 (2): 49-65.

Cruz, María Angélica. 2004. Iglesia, represión y memoria: el caso chileno. Madrid, España: Siglo XXI. 
Ema, José H. 2004. "Del Sujeto a la Agencia (a través de lo Político)», Athenea Digital, 5: 1-24. Disponible en: http://www.raco.cat/index.php/Athenea/article/viewFile/34133/33972 (Consulta: 12 de agosto de 2015).

García Agustín, Óscar y Félix Aguirre. 2014. «Spatial practices and narratives: The GenkiDama for Education by Chilean Students», Journal of Language and Politics, 13 (4): 732-745.

Halbwachs, Maurice. 2004. La memoria colectiva. Zaragoza: Prensas Universitarias de Zaragoza.

Hatibovic, Fuad; Juan Sandoval y Manuel Cárdenas. 2012. «Posiciones de sujeto y acción política universitaria: análisis del discurso de estudiantes de universidades de la región de Valparaíso", Última Década, 20 (37): 111-134.

Hirsch, Marianne. 2008. "The Generation of Postmemory», Poetics Today 29 (1): 103-128.

Hite, Katherine. 2003. «El monumento a Salvador Allende en el debate político chileno», en E. Jelin y V. Langland (eds.), Monumentos, memoriales y marcas territoriales. Madrid: Siglo XXI.

Hite, Katherine. 2013. Politica y arte de la conmemoración. Memoriales en América Latina y España. Santiago: Madrágora.

Íñiguez, Lupicinio y Charles Antaki. 1998. "Análisis del discurso», Anthropos, 177: 59-66.

Jara, Daniela. 2013. The Aftermath of Political Violence: The Opposition's Second Generation in the Post-Coup Chile and its Familial Memory [tesis]. London: University of London.

Jelin, Elizabeth. 2002. Los trabajos de la memoria. Madrid: Siglo XXI España Editores.

Jelin, Elizabeth y Victoria Langland (eds.). 2003. Monumentos, memoriales y marcas territoriales. Madrid: Siglo XXI.

Juárez, María José y Catalina Salanova. 2009. «Lugares de memoria y formas estéticas: narraciones desde los jóvenes», Praxis, 11 (15): 209-217.

Judt, Tony. 2010. Postguerra. Una historia de Europa desde 1945. Madrid: Taurus.

Lazzara, Michael. 2003. «Tres recorridos de Villa Grimaldi», en Elisabeth Jelin y Victoria Langland (eds.), Monumentos, memoriales y marcas territoriales. Madrid: Siglo XXI.

Lechner, Norbert. 2002. Las sombras del mañana: la dimensión subjetiva de la política. Santiago, Chile: LOM.

Le Quintrec, Gillaume y Pierre Geiss. 2006. Manuel d'histoire franco-allemand: L'Europe et le monde depuis 1945. Paris: Nathan.

McDowel, Sara y Máire Braniff. 2014. Commemoration as conflic. Space, memory and identity in peace procesess. New York: Palgrave McMillan.

Mannheim, Karl. 1993. "El problema de las generaciones», Revista Española de Investigaciones Sociológicas, 62: 193-242.

Martuccelli, Danilo. 2007. Lecciones de sociología del individuo. Lima: Departamento de Ciencias Sociales de la Universidad Católica del Perú. 
Middleton, David y Derek Edwards. 1990. Memoria compartida. La naturaleza del recuerdo y del olvido. Barcelona: Paidós.

Monsiváis, Alejandro. 2008. «La ciudadanía a debate: memoria, no-dominación y esfera pública», en Ileana Rodríguez y Mónica Szurmuk (eds.), Memoria y Ciudadanía. Santiago, Chile: Cuarto Propio.

Nora, Pierre. 2009. Pierre Nora en Les lieux de mèmoire. Santiago, Chile: LOM.

Piper, Isabel y Evelyn Hevia. 2013. Espacio y recuerdo: archipiélago de memorias en Santiago de Chile. Santiago, Chile: Ocho Libros.

Piper, Isabel. 2015. Violencia política, miedo y amenaza en lugares de memoria. Athenea Digital, 15 (4): 155-172.

Piper Isabel; María José Reyes y Roberto Fernández. 2012. «Women and public space: psychosocial analysis of the monument 'women in memory'", Feminism and Pschology, 22 (2): 249-260.

Piper Isabel; María José Reyes; Catalina Arteaga y Marcia Escobar. 2009. Usos del espacio, identidades sociales y políticas del recuerdo: análisis psicosocial de lugares de memoria de los conflictos violentos de nuestro pasado reciente. Proyecto Fondecyt No 1070926

Programa de Derechos Humanos. 2010. Geografia de la memoria. Ministerio del Interior.

Radstone, Susannah. 2008. "Memory studies: For and against», Memory Studies, 1 (1): 31-39.

Ranciére, Jaques. 1996. El desacuerdo. Política y filosofía. Buenos Aires: Ediciones Nueva Visión.

Raposo, Gabriela. 2012. "Territorios de la memoria: la retórica de la calle en Villa Francia», Polis, 9 (31): 1-15.

Reguillo, Rossana. 2003. "Las culturas juveniles, un campo de estudio. Breve agenda para la discusión», Revista Brasileira de Educação, 23: 103-118.

Reyes, María José. 2009. "Generaciones de memoria: una dialógica conflictiva», Praxis, 11 (15): 77-97.

Reyes, María José. 2012. Políticas de memoria desde una clave generacional: el pasado reciente de Chile (1970-1990) en trayectos cotidianos juveniles. Proyecto FONDECYT no 11121405.

Reyes, María José; Juan Muñoz y Félix Vázquez. 2013. «Políticas de Memoria Desde los Discursos Cotidianos: la Despolitización del Pasado Reciente en el Chile Actual», Psykhe, 22 (2): 161-173.

Reyes, María José; Marcela Cornejo; Angélica Cruz; Constanza Carrillo y Patricio Caviedes. 2015. "Dialogía intergeneracional en la construcción de memorias acerca de la dictadura militar chilena», Universitas Psychologica, 14 (1): 255-270.

Ricoeur, Paul. 2003. La memoria, la historia, el olvido. Madrid: Trotta.

Rilla, José. 2009. «Prólogo. Historias en segundo grado. Pierre Nora y los lugares de la memoria», en Pierre Nora, Les lieux de mémoire. Santiago: LOM, Trilce.

Sa'adah, Anne. 1998. Germany's second chance: Truth, justice and democratization. Cambridge MA: Harvard University Press. 
Sampedro, Víctor y Alejandro Baer. 2003. «El recuerdo como olvido y el pasado extranjero. Padres e hijos ante la memoria histórica mediatizada», Revista de Estudios de Juventud, edición especial: 93-108.

Sarlo, Beatriz. 2007. Tiempo pasado. Cultura de la memoria y giro subjetivo. Una discusión. Buenos Aires: Siglo XXI

Sepúlveda, Mauricio; Andrea Sepúlveda; Isabel Piper y Lelya Troncoso. 2015. «Lugares de memoria y agenciamientos generacionales: lugar, espacio y experiencia», Ultima Década, 42: 93-113.

Snow, David A. y Robert Benford. 1992. "Master Frames and Cycles of Protest.», en Aldon D. Morris y Carol McClurg (eds.), Frontiers in Social Movement Theory. New Haven: Yale University Press.

Struken, Marita. 2008. "Memory, consumerism and the media: Reflections on the emergence of the field", Memory Studies, 1 (1): 73-78.

Tilly, Charles. 1992. Coercion, capital and European states: AD 990-1992. London: Blakwell.

Toledo, María Isabel; Diana Veneros y Abrahm Magendzo. 2006. Lugares de la memoria: activación de la memoria colectiva a través de la visita de estudiantes al Parque Por la Paz Villa Grimaldi. Santiago de Chile: Universidad Diego Portales.

Traverso, Enzo. 2007. El pasado, instrucciones de uso: historia, memoria, política. Madrid: Marcial Pons.

Vázquez, Félix. 2001. La memoria como acción social: relaciones, significados e imaginario. Barcelona: Paidós.

Vázquez, Félix. 2002. «Construyendo el pasado: la memoria como práctica social», Estudios Centroamericanos, 649-650: 1049-1065.

Vinyes, Ricard. 2007. "La memòria com a política pública», I Coloqui Internacional Memorial Democràtic: Polítiques Públiques de la Mèmoria, Barcelona.

Wertsch, J. V. 2002. Voices of collective remembering. Cambridge: Cambridge University Press.

Young, James. 2000a. At Memory's Edge: After-images of the Holocaust in Contemporary Art and Architecture. New Haven and London: Yale University Press.

Young, James 2000b. "Cuando las piedra hablan», Puentes, 1 (1): 80-93.

Presentado para evaluación: 7 de enero de 2016.

Aceptado para publicación: 13 de junio de 2016.

\section{MARÍA J. REYES}

mjrandreani@u.uchile.cl

Doctora en Psicología Social por la Universidad Autónoma de Barcelona. Profesora asistente de la Universidad de Chile (Facultad de Ciencias Sociales, Departamento de Psicología). Directora del Núcleo de Investigación sobre Vidas Cotidianas en Emergencia: Territorio, Habitantes y Prácticas. Su línea de investigación versa sobre la 
construcción de memorias sociales y vida cotidiana, transmisión intergeneracional de memorias y políticas de memoria desde la cotidianidad.

MARÍA A. CRUZ

mariaangelica.cruz@uv.cl

Doctora en Sociología por la Universidad Complutense de Madrid. Profesora adjunta de la Universidad de Valparaíso (Facultad de Humanidades, Instituto de Sociología). Investigadora responsable y coinvestigadora de cuatro proyectos de investigación FONDECYT y miembro permanente del claustro del doctorado en Estudios Interdisciplinarios de la Universidad de Valparaíso. Sus líneas de investigación mezclan las áreas de las epistemologías feministas, memorias sociales de la dictadura chilena, relaciones entre ciencia y política y metodologías cualitativas de la investigación social.

FÉLIX J. AGUIRRE

felix.aguirre@uv.cl

Doctor en Ciencias Políticas y Sociología por la Universidad Complutense de Madrid. Profesor titular de la Universidad de Valparaíso (Facultad de Humanidades, Instituto de Sociología). Director alterno del Núcleo de Investigación sobre Cultura Política Contemporánea y Espacio Público y miembro permanente del claustro del doctorado en Estudios Interdisciplinarios de la Universidad de Valparaíso. Durante estos últimos cinco años ha publicado diferentes trabajos relacionados con el área de investigación de la cultura política contemporánea, que pueden encontrarse en las siguientes revistas de corriente principal: Polis, Revista Mexicana de Sociología, Sociologia y Politica, The Journal of Language and Politics, Ideas y Valores. 